\title{
Extra Corporeal Membrane Oxygenation (ECMO) for Patients with COVID-19
}

\author{
David T McGreevy MD and Jenny Seilitz MD \\ Department of Cardiothoracic and Vascular Surgery, Faculty of Medicine and Health, \\ Örebro University Hospital and Örebro University, Örebro, Sweden
}

Severe Acute Respiratory Syndrome Coronavirus 2 (SARS-COV-2), also known as Coronavirus disease 2019 (COVID-19), has spread worldwide since December 2019 and has presented serious challenges to healthcare systems. As of 15 April 2020, over 2 million people have been diagnosed with COVID-19 worldwide, with over 130,000 having died. A total of 11,927 patients have been diagnosed in Sweden, 954 have required intensive care and 1,203 have deceased. Admission to intensive care is after an average of 10.5 days, $75 \%$ are men with a mean age of 59 years [1]. To date, there is no effective therapy for the treatment of this disease and its management mainly focuses on preventing its spread. Severe symptoms with respiratory failure or acute respiratory distress syndrome (ARDS) develop in about 20\% of cases with the principal therapy being lung protective ventilation, prone position, restrictive fluid management and adequate management of organ failure [2,3]. The mortality rate in those requiring mechanical ventilation is high. Extracorporeal membrane oxygenation (ECMO) can provide artificial respiratory or cardiac support to patients without effective gas exchange and systemic perfusion and has in some studies shown improved survival rates in patients with ARDS. However, it is recommended as a rescue strategy as part of the Endovascular Resuscitation and Trauma Management (EVTM) concept when other treatment options have failed [4-6]. ECMO was used during the Influenza A (H1N1) pandemic in 2009 for the treatment of ARDS and was associated

\section{Corresponding author:}

David T McGreevy, Department of Cardiothoracic and Vascular Surgery, Örebro University Hospital, SE-701 85 Örebro, Sweden. Email: david.mcgreevy@regionorebrolan.se

(c) 2020 CC BY 4.0 - in cooperation with Depts. of Cardiothoracic/ Vascular Surgery, General Surgery and Anesthesia, Örebro University Hospital and Örebro University, Sweden with a lower in-hospital mortality of $21-24 \%[7,8]$. Similar findings were reported with the use of ECMO in $5.8 \%$ of patients treated for refractory respiratory failure caused by Middle East Respiratory Syndrome [9]. Initial data show the World Health Organization guidelines on the management of patients with ARDS from COVID-19 suggest that veno-venous (VV) ECMO should be considered for patients with fulminant lung failure and refractory hypoxemia despite lung protective ventilation. The number of patients who require this level of support is currently unknown [10]. Henry et al. recently published an article with a pooled analysis of available data reporting a $7.2 \%$ use of ECMO due to ARDS from COVID-19 and a mortality rate of $94.1 \%$ with no significant difference compared with conventional therapy [11]. This early report would suggest that ECMO neither harms nor benefits critical patients with COVID-19. However, the small sample size $(n=17)$ as well as the limited data on disease severity should be taken into consideration, remembering that this is an ongoing pandemic with many patients still being treated with ECMO. An early report by Ruan et al. showed increased levels of interleukin-6 and decreased levels of lymphocytes in patients dying from COVID-19 [12]. These are changes that are regularly observed during ECMO which is why the immunological status of patients with COVID-19 should be considered before starting ECMO treatment [13,14]. It is important to remember that patients with COVID-19 may also become critically ill through septic shock, multiorgan failure or the exacerbation of comorbid diseases, and ECMO may be of limited use in such cases. However, little is still known about these different subsets of patients; experience of using ECMO is limited and should therefore only be performed by expert centres with a sufficient case volume to ensure clinical expertise $[15,16]$. It has also been reported that severe COVID-19 patients are hypercoagulable, that disseminated intravascular 


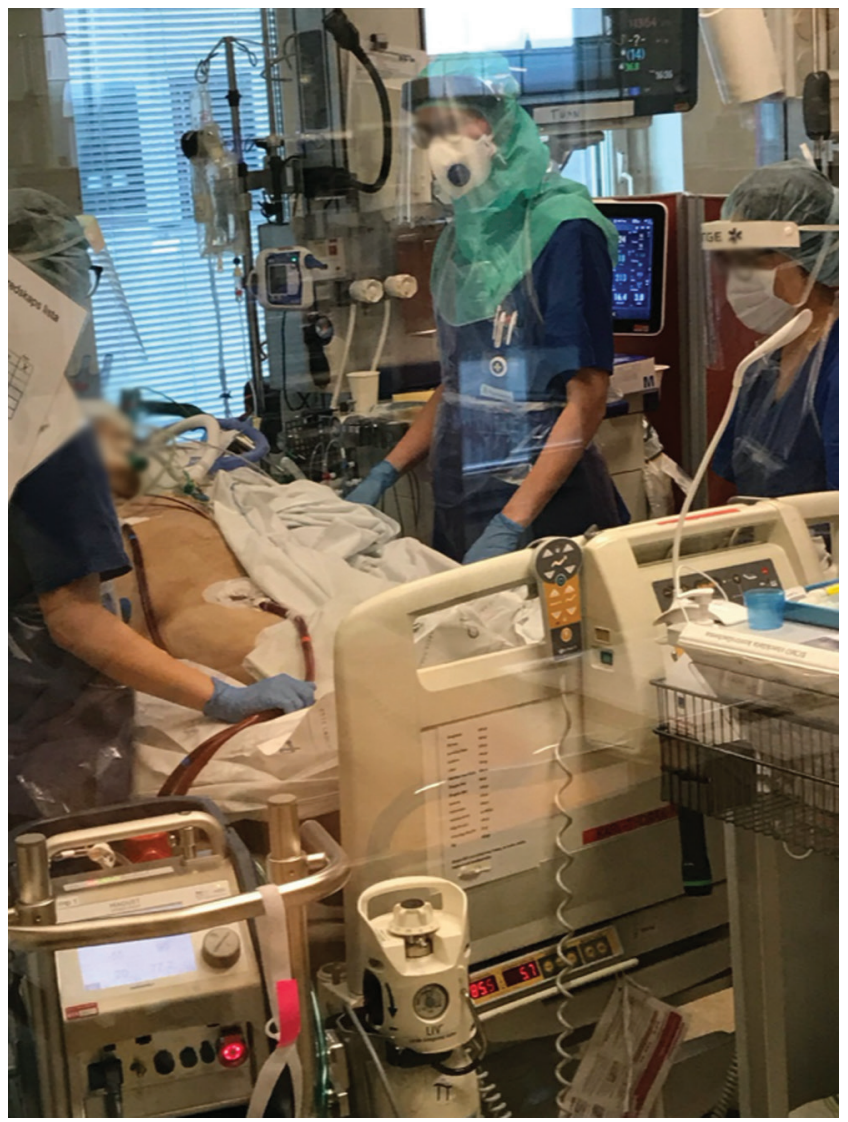

Figure 1 Patient on VV-ECMO at Örebro University Hospital because of fulminant lung failure and refractory hypoxemia caused by COVID-19.

coagulation may exist in the majority of deaths and that early anticoagulation therapy may be associated with increased survival $[17,18]$. This is an important consideration since ECMO can be associated with both haemorrhage and thrombosis [19]. As a response to this lack of evidence, the Extracorporeal Life Support Organization (ELSO) Registry is now in the process of adapting to include information regarding the use of ECMO in the treatment of COVID-19 patients and prospective observational studies will follow. ELSO has also released guidelines on the use of ECMO in the treatment of COVID-19 patients that are frequently updated. They highlight specific consideration for patient selection, deeming ECMO solely suitable in young, previously healthy COVID-19 patients with single organ failure only after maximizing traditional therapies at available ECMO centres with appropriate organization of trained personnel, equipment, facilities and routines [20].

\section{Ethics Statement}

(1) All the authors mentioned in the manuscript have agreed to authorship, read and approved the manuscript, and given consent for submission and subsequent publication of the manuscript.
(2) The authors declare that they have read and abided by the JEVTM statement of ethical standards including rules of informed consent and ethical committee approval as stated in the article.

\section{Conflicts of Interest}

The authors declare that they have no conflicts of interest.

\section{Funding}

The authors received no financial support for the research, authorship, and/or publication of this article.

\section{Author Contributions}

DM drafted the manuscript. JS contributed to the manuscript.

\section{REFERENCES}

[1] COVID-19 i svensk intensivvård. https://www.icuregswe.org/data--resultat/covid-19-i-svensk-intensivvard/. Accessed 15 April 2020.

[2] Bein B, Bachmann M, Huggett S, Wegermann P. SARSCoV-2/COVID-19: empfehlungen zu diagnostik und therapie [SARS CoV-2/COVID-19: evidence-based recommendation on diagnosis and therapy]. Anasthesiol Intensivmed Notfallmed Schmerzther. 2020;55(4):257-65.

[3] Alhazzani W, Møller MH, Arabi YM, et al. Surviving Sepsis Campaign: guidelines on the management of critically ill adults with coronavirus disease 2019 (COVID-19). Intensive Care Med. 2020;1-34. In Press. doi:10.1007/ s00134-020-06022-5.

[4] Hörer T. Resuscitative endovascular balloon occlusion of the aorta (REBOA) and endovascular resuscitation and trauma management (EVTM): a paradigm shift regarding hemodynamic instability. Eur J Trauma Emerg Surg 2018;44:487-9.

[5] Rosenberg AA, Haft JW, Bartlett R, et al. Prolonged duration ECMO for ARDS: futility, native lung recovery, or transplantation? ASAIO J. 2013;59:642-50.

[6] Goligher EC, Tomlinson G, Hajage D, et al. Extracorporeal membrane oxygenation for severe acute respiratory distress syndrome and posterior probability of mortality benefit in a post hoc Bayesian analysis of a randomized clinical trial. JAMA. 2018;320(21):2251-9.

[7] Noah MA, Peek GJ, Finney SJ, et al. Referral to an Extracorporeal membrane oxygenation center and mortality among patients with severe 2009 Influenza A(H1N1). JAMA. 2011;306:1659-68.

[8] The Australia and New Zealand Extracorporeal Membrane Oxygenation (ANZ ECMO) Influenza Investigators. Extracorporeal membrane oxygenation for 2009 influenza $\mathrm{A}(\mathrm{H} 1 \mathrm{~N} 1)$ acute respiratory distress syndrome. JAMA. 2009;302:188895.

[9] Alshahrani MS, Sindi A, Alshamsi F, et al. Extracorporeal membrane oxygenation for severe Middle East respiratory syndrome coronavirus. Ann Intensive Care. 2018;8:3. 
[10] Combes A, Brodie D, Bartlett R, et al. Position paper for the organization of extracorporeal membrane oxygenation programs for acute respiratory failure in adult patients. Am J Respir Crit Care Med. 2014;190(5):488-96.

[11] Henry BM, Lippi G. Poor survival with extracorporeal membrane oxygenation in acute respiratory distress syndrome (ARDS) due to coronavirus disease 2019 (COVID-19): pooled analysis of early reports. J Crit Care. In Press. 2020;58:27-8.

[12] Ruan Q, Yang K, Wang W, Jiang L, Song J. Clinical predictors of mortality due to COVID-19 based on an analysis of data of 150 patients from Wuhan, China. Intensive Care Med. 2020. doi: 10.1007/s00134-020-05991-x [Epub ahead of print].

[13] Bizzarro MJ, Conrad SA, Kaufman DA, Rycus P. Infections acquired during extracorporeal membrane oxygenation in neonates, children, and adults. Pediatr Crit Care Med. 2011;12(3):277-81.

[14] Risnes I, Wagner K, Ueland T, Mollnes T, Aukrust P, Svennevig J. Interleukin-6 may predict survival in extracorporeal membrane oxygenation treatment. Perfusion. 2008;23(3): 173-8.
[15] Munshi L, Walkey A, Goligher E, Pham T, Uleryk EM, Fan E. Venovenous extracorporeal membrane oxygenation for acute respiratory distress syndrome: a systematic review and meta-analysis. Lancet Respir Med. 2019;7(2):163-72.

[16] Barbaro RP, Odetola FO, Kidwell KM, et al. Association of hospital-level volume of extracorporeal membrane oxygenation cases and mortality. Analysis of the extracorporeal life support organization registry. Am J Respir Crit Care Med. 2015;191(8):894-901.

[17] Tang N, Li D, Wang X, Sun Z. Abnormal coagulation parameters are associated with poor prognosis in patients with novel coronavirus pneumonia. J Thromb Haemost. 2020; 18(4):844-847.

[18] Tang N, Bai H, Chen X, Gong J, Li D, Sun Z. Anticoagulant treatment is associated with decreased mortality in severe coronavirus disease 2019 patients with coagulopathy. J Thromb Haemost. 2020; In Press. Doi: 10.1111/jth.14817.

[19] Thomas J, Kostousov V, Teruya J. Bleeding and thrombotic complications in the use of extracorporeal membrane oxygenation. Semin Thromb Hemost. 2018;44(1):20-29.

[20] ECMO in COVID-19. https://www.elso.org/COVID19. aspx. Accessed 15 April 2020. 